\title{
Disintegration of microtubules in Arabidopsis thaliana and bladder cancer cells by isothiocyanates
}

\author{
Anders Øverby ${ }^{*}$, Mette S. Bævre ${ }^{\ddagger}$, Ole P. Thangstad ${ }^{\dagger}$ and Atle M. Bones*
}

Department of Biology, Norwegian University of Science and Technology (NTNU), Trondheim, Norway

Edited by:

Jose Manuel Estevez, University of

Buenos Aires, Argentina

Reviewed by:

Uener Kolukisaoglu, University of

Tuebingen, Germany

Vasileios Fotopoulos, Cyprus

University of Technology, Cyprus

\section{${ }^{*}$ Correspondence:}

Anders Øverby and Atle M. Bones,

Department of Biology, Norwegian

University of Science and

Technology (NTNU), Hogskoleringen

5, N-7491 Trondheim, Norway

e-mail: anders.overby@ntnu.no;

atle.bones@ntnu.no

${ }^{\ddagger}$ Present address:

Mette S. Bævre, Institute for Cancer

Genetics and Informatics, Oslo

University Hospital, Montebello,

Norway

${ }^{\S}$ These authors have contributed equally to this work.

${ }^{\dagger}$ In loving memory of Ole

P. Thangstad.
Isothiocyanates (ITCs) from biodegradation of glucosinolates comprise a group of electrophiles associated with growth-inhibitory effects in plant- and mammalian cells. The underlying modes of action of this feature are not fully understood. Clarifying this has involved mammalian cancer cells due to ITCs' chemopreventive potential. The binding of ITCs to tubulins has been reported as a mechanism by which ITCs induce cell cycle arrest and apoptosis. In the present study we demonstrate that ITCs disrupt microtubules in Arabidopsis thaliana contributing to the observed inhibited growth phenotype. We also confirmed this in rat bladder cancer cells (AY-27) suggesting that cells from plant and animals share mechanisms by which ITCs affect growth. Exposure of $A$. thaliana to vapor-phase of allyl ITC (AITC) inhibited growth and induced a concurrent bleaching of leaves in a dose-dependent manner. Transcriptional analysis was used to show an upregulation of heat shock-genes upon AITC-treatment. Transgenic A. thaliana expressing GFP-marked $\alpha$-tubulin was employed to show a time- and dose-dependent disintegration of microtubules by AITC. Treatment of AY-27 with ITCs resulted in a time- and dose-dependent decrease of cell proliferation and $\mathrm{G}_{2} / \mathrm{M}$-arrest. AY-27 transiently transfected to express GFP-tagged $\alpha$-tubulin were treated with ITCs resulting in a loss of microtubular filaments and the subsequent formation of apoptotic bodies. In conclusion, our data demonstrate an ITC-induced mechanism leading to growth inhibition in A. thaliana and rat bladder cancer cells, and expose clues to the mechanisms underlying the physiological role of glucosinolates in vivo.

Keywords: isothiocyanates, plant defense, Arabidopsis thaliana, bladder cancer, glucosinolate-myrosinase pathway

\section{INTRODUCTION}

Naturally occurring isothiocyanates (ITCs) are plant phytochemicals associated with cytotoxicity in several cell types including plant- and mammalian cells. These electrophilic compounds confer a reactive $-\mathrm{N}=\mathrm{C}=\mathrm{S}$ group linked to an $\mathrm{R}$ moiety influencing the potency. ITCs are found in several cruciferous edibles including mustards, broccoli, cauliflower and brussel sprouts in which they are stored as their inert precursor glucosinolate (Kissen and Bones, 2009). Glucosinolates are hydrolyzed by myrosinases upon damage of plant tissue releasing volatile ITCs causing a strong smell and a pungent taste repelling herbivores from further consuming the plant (Halkier and Gershenzon, 2006). Previous studied ITCs include sulforaphane (SFN), methyl ITC (MITC), allyl ITC (AITC), butyl ITC (BuITC), benzyl ITC (BITC), and phenethyl ITC (PEITC; Figure 1A).

ITCs are known to be potent chemopreventives possessing the ability to both prevent and inhibit tumorigenesis (Nakamura, 2009). The preventive effect has been shown through epidemiological studies in which an inverse association between the intake of ITC-producing cruciferous vegetables and development of cancer in lung, breast, colon, prostate and bladder was observed (London et al., 2000; Seow et al., 2002; Ambrosone et al., 2004; Joseph et al., 2004; Brennan et al., 2005; Tang et al., 2008).
Inhibition of cancer cell growth has been shown through studies of in vitro cell cultures and in vivo studies using animal models (Zhang, 2004; Cheung and Kong, 2010). Furthermore, ITCs have been clinically trialed emphasizing their potential as chemopreventives (Shapiro et al., 2006; Cornblatt et al., 2007).

In plants, ITCs have been linked to growth inhibition involving the use of ITCs directly or by using materials and extracts containing both glucosinolate substrates and the enzymes involved in degradation (Wolf et al., 1984; Bialy et al., 1990; Vaughn and Boydston, 1997; Norsworthy and Meehan, 2005). Plants shown to be affected by ITCs include wheat, lettuce, velvet leaf, palmer amaranth and the model plant Arabidopsis thaliana (Wolf et al., 1984; Bialy et al., 1990; Yamane et al., 1992; Norsworthy and Meehan, 2005; Hara et al., 2010). Studies with ITCs on plants have particularly focused on weed control at which ITCs or ITCproducing entities constitute promising agents (Boydston and Hang, 1995; AlKhatib et al., 1997; Haramoto and Gallandt, 2005; Norsworthy et al., 2006). In A. thaliana, it has been shown that exogenously applied ITCs inhibit growth and induce bleaching of leaves (Hara et al., 2010). In addition, it was reported that AITC induces a stomatal closure in A. thaliana pointing toward a physiological role in the plant's defense system against water loss and pathogenic intruders (Khokon et al., 2011). More recently, Hara 


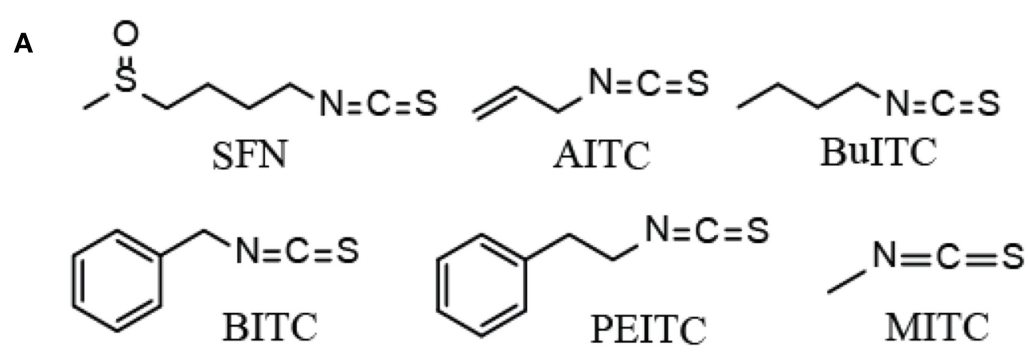

\section{Days after AITC-exposure}

B 1

3
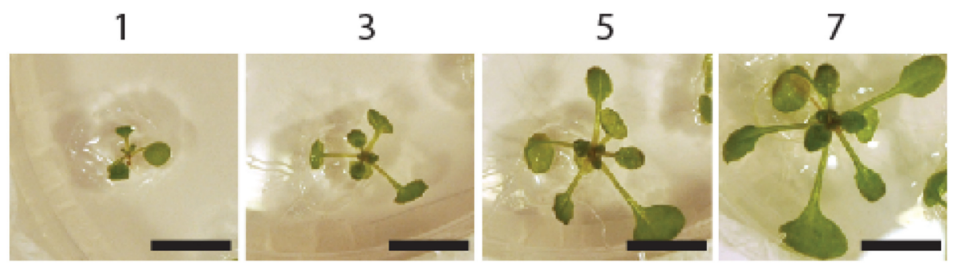

0.1
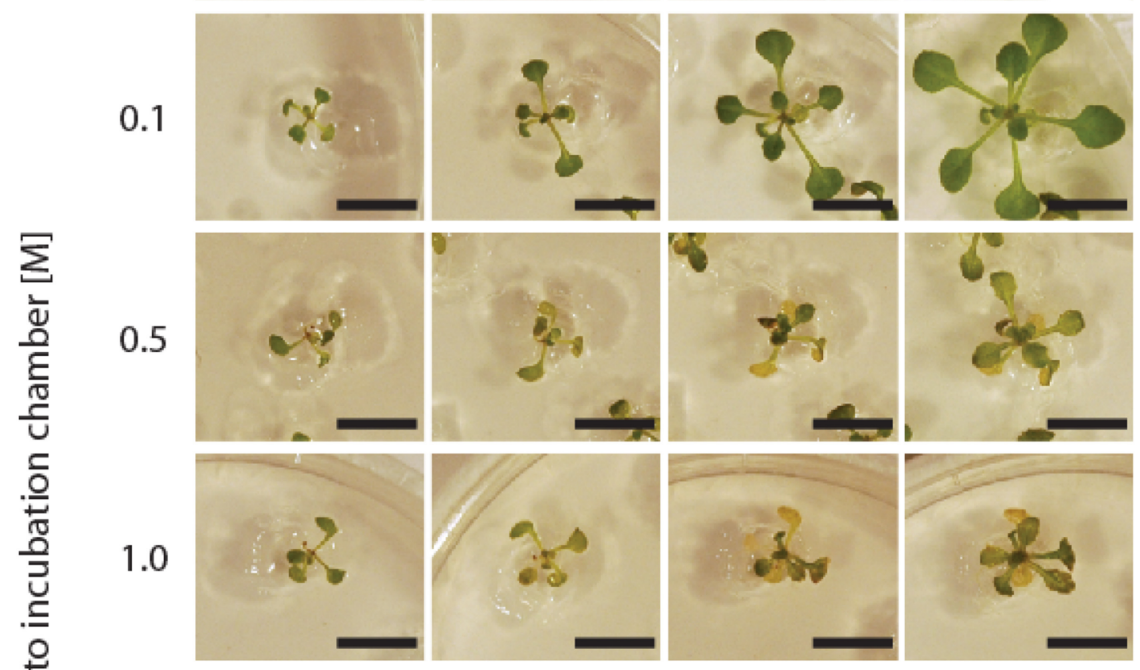

1.0
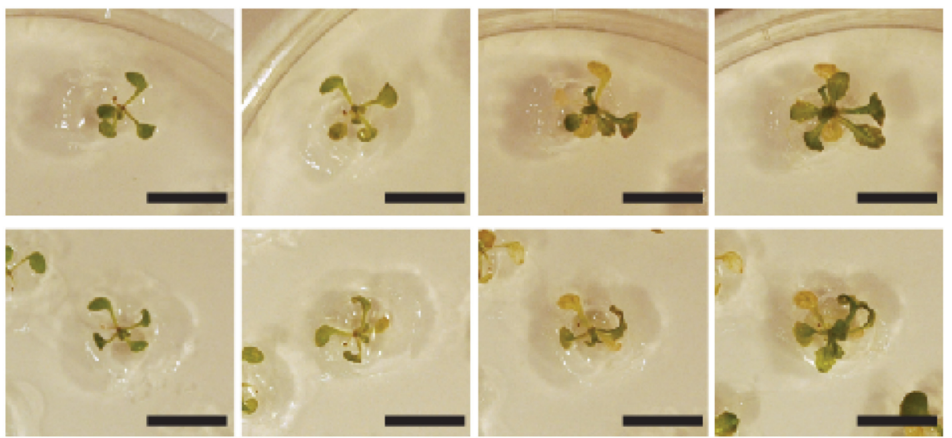

1.5
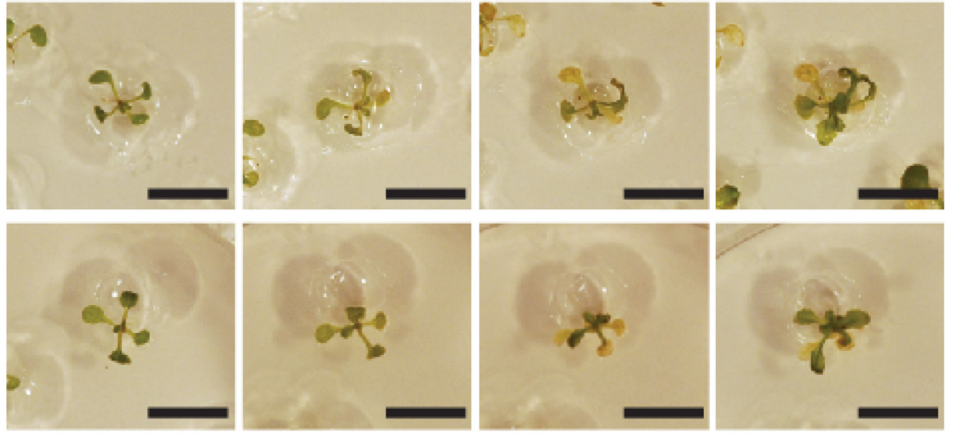

1.9
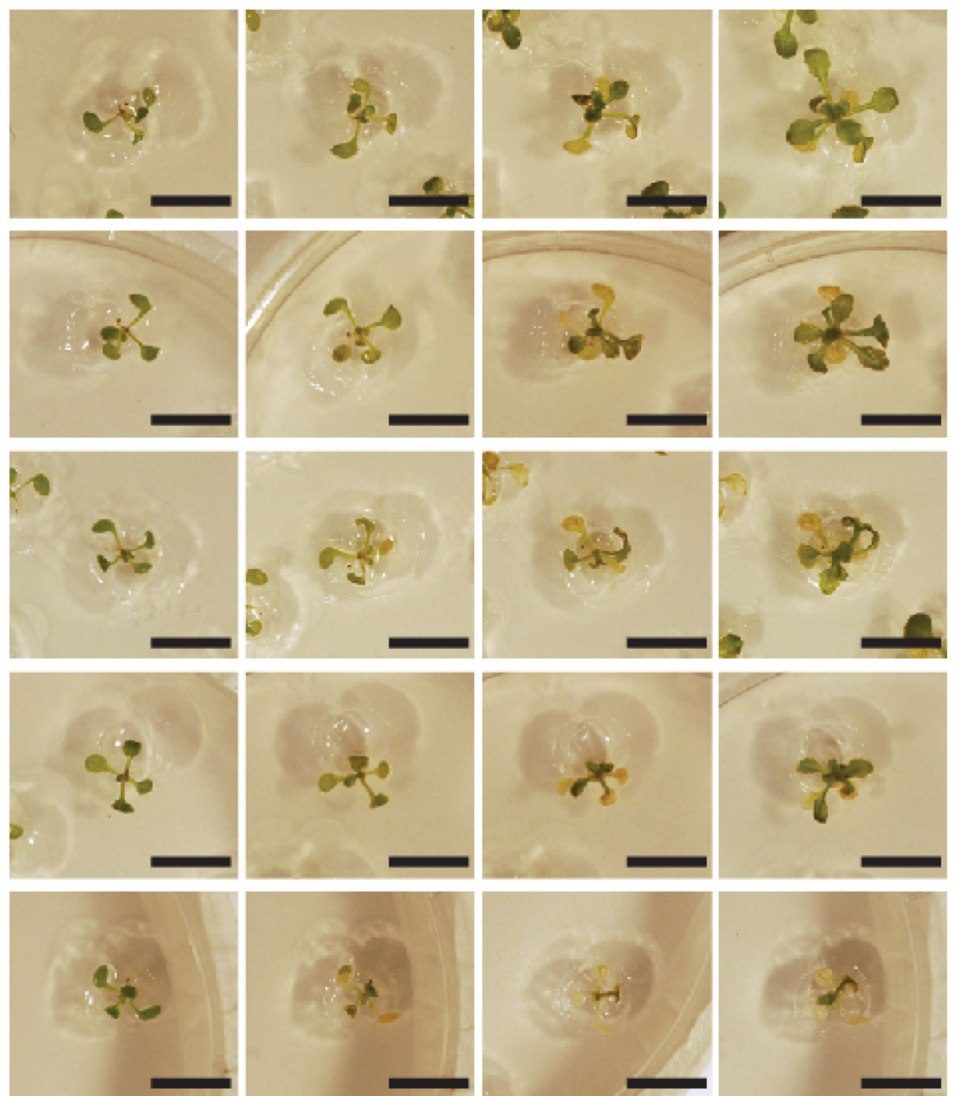

3.4
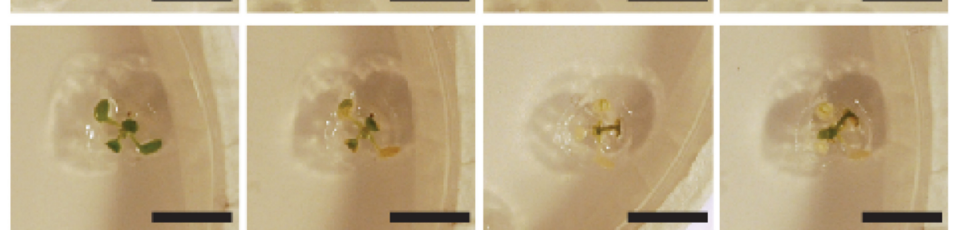

FIGURE 1 | Dose dependent inhibition of $\boldsymbol{A}$. thaliana growth. (A) Chemical structures of ITCs. (B) Effect of 0.1-3.4M AITC on growth phenotype of 11-days old $A$. thaliana. Attenuated growth and bleaching of leaves were distinct from $0.5 \mathrm{M}$ treatment. $\mathrm{Bar}=1 \mathrm{~cm}$. 
and colleagues reported an increased heat tolerance of $A$. thaliana by PEITC presumably through elevating the expression levels of genes encoding heat shock proteins (Hara et al., 2013).

The majority of experiments aimed at elucidating the cellular effects caused by ITCs have been conducted using mammalian cell systems, leaving the mechanism of action in plant cells rather unexplored in comparison. From studies with cancer cells, several ITC-induced chemopreventive mechanisms have been identified (Navarro et al., 2011). Although various upstream events are implicated by ITCs, it is well-established that the induction of cell cycle arrest and/or ultimately programmed cell death is important in inhibition of cancer cell growth. Mi and colleagues reported the binding of ITCs to $\alpha$ - and $\beta$-tubulin as an important mechanism of inducing a mitotic cell cycle arrest and subsequently apoptosis in human lung cancer cells (Mi et al., 2008). These findings have also been reported in human bladder cancer cells where tubulin bound to ITCs were ubiquitin-marked for degradation causing microtubules to disrupt (Geng et al., 2011).

In the present study we showed that ITCs disrupt microtubular filaments in A. thaliana contributing to the observed inhibited growth phenotype. We also confirmed the same findings in rat bladder cancer cell AY-27 leading to apoptosis suggesting that ITCs induce similar upstream events in different cell types by targeting highly conserved proteins such as tubulins. Gained insight into the ITC-induced cellular effects in plants will aid in an improved understanding of the physiological role of the glucosinolate-myrosinase system and may also lead to novel approaches to further exploration and development of ITCs as chemopreventives.

\section{RESULTS}

\section{AITC INHIBITS GROWTH OF A. THALIANA IN A DOSE-DEPENDENT MANNER}

Exposure of 11-days old plants of $A$. thaliana wild-type to the vapor-phases of AITC-dilutions in the concentration range 0.13.4 $\mathrm{M}$ inhibited growth in a dose-dependent manner (Figure 1B). The observed growth reduction was concurrent with bleaching of leaves, and visible from the exposure of $0.5 \mathrm{M}$ AITC and higher concentrations. New plant tissue developed after AITCtreatment, however, did not display bleaching or miscoloring. As the extent of bleaching presumably reflects the impact caused by AITC, it is noteworthy how some exposed plants managed to recover as seen from $3.4 \mathrm{M}$ exposure in Figure 1B. Lack of recovery was observed for plants exposed to vapor-phases of 4.9 and 9.7 M AITC resulting in a complete bleaching of whole plants 1 day after exposure (data not shown). A previous study has reported an ITC-induced growth inhibition and bleaching of leaves of 5-weeks old $A$. thaliana by spraying the plants with water-emulsions of ITCs (Hara et al., 2010). When employing this method, we obtained no or only weak responses in growth phenotype combined with poor reproducibility likely due to the unstable nature of ITCs in water (Ohta et al., 1995) and an uneven distribution of ITCs from spraying (data not shown). Consequently, we favored a different approach in which the volatility of AITC was exploited to generate an even atmospheric distribution of AITC in a closed growth chamber. This method yielded distinct effects on growth phenotypes from various AITC-concentrations as depicted in Figure 1B, combined with a significantly increased reproducibility. When including another aliphatic ITC, butyl ITC (BuITC), a significantly weaker response on growth was observed compared to AITC (Figure 2A). Adding the aromatic benzyl ITC (BITC) and phenethyl ITC (PEITC) resulted in no or weak responses (Figure 2B). The differences between the potential of ITCs to inhibit growth, however, are more likely explained through their different vapor pressures rather than the potentials of the ITCs to affect growth (AITC, 493; BuITC, 340; BITC, 2.0; PEITC, $1.5 \mathrm{~Pa}$ ). Collectively, these data show that AITC induces growth inhibition and bleaching of leaves in A. thaliana in a dose-dependent manner and that these effects are not restricted to AITC but also induced by other ITCs e.g., BuITC.

\section{DISINTEGRATION OF MICROTUBULAR FILAMENTS IN A. THALIANA BY ITCs}

For investigating the effect of ITC on microtubules in A. thaliana, we employed a transgenic line expressing green fluorescent protein (GFP) fused to the N-terminal end of $\alpha$-tubulin (Ueda et al., 1999). Growth phenotype of this line was shown to be unaffected by the genetic alteration when compared to wild-type following AITC-treatments (data not shown). The fusion protein rendered the microtubular filaments visible in confocal scanning

A BulTC added to incubation chamber [M]

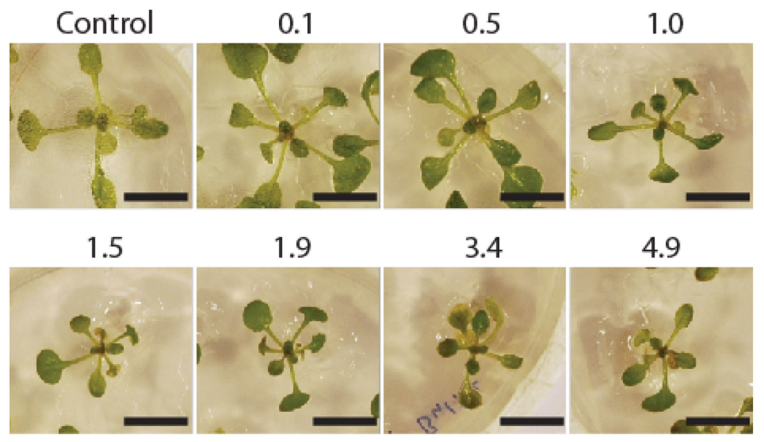

B BITC added to incubation chamber [M]

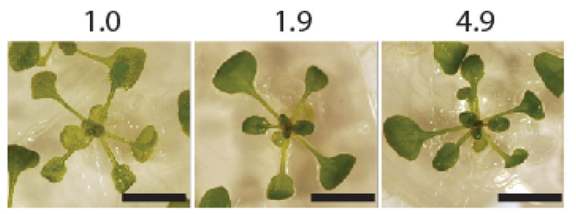

PEITC added to incubation chamber [M]

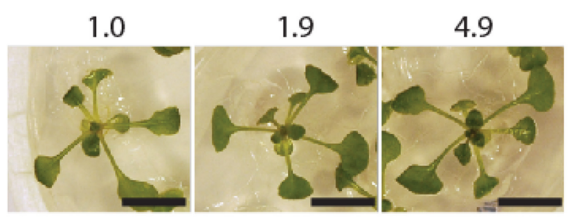

FIGURE 2 | Effect of BuITC, BITC, and PEITC on A. thaliana growth. (A) Vapor-phase of BulTC inhibits growth of 10-days old $A$. thaliana when added to incubation chamber in the concentration $1.0 \mathrm{M}$. Significant reduction in plant size was observed for all concentrations 1.0-4.9 M BulTC. (B) Weak or no response on $A$. thaliana growth by BITC and PEITC added to the incubation chamber in concentration range $1.0-4.9 \mathrm{M}$. Bar $=1 \mathrm{~cm}$. 
microscope as shown in Figure $\mathbf{3 A}$, and proved to be unaltered after $90 \mathrm{~min}$ of exposure to rapeseed oil without ITC. A rapid loss of the filaments was observed when plants were exposed to vapor-phase of $4.9 \mathrm{M}$ AITC for $2 \mathrm{~min}$ (Figure 3B). Microtubule filaments were significantly reduced but still detectable when AITC-concentration was decreased to $1.5 \mathrm{M}$, and when $0.5 \mathrm{M}$ AITC was applied the filaments were seemingly unaffected after 2 min of exposure (Figure 3B). These findings indicate that ITCinduced loss of microtubules in A. thaliana is dose-dependent. The disintegration also developed in a time-dependent fashion. Exposure of plants to vapor of $0.5 \mathrm{M}$ AITC for $5 \mathrm{~min}$ did not reduce the filaments, but an incubation time of $10 \mathrm{~min}$ strongly reduced the number of filaments (Figure 3C). After $30 \mathrm{~min}$ of $0.5 \mathrm{M}$ exposure the filaments were completely absent (Figure 3C). In order to show that the breakdown of microtubules in A. thaliana was not restricted to AITC we repeated the experiments with BuITC, BITC, and PEITC. As expected based on the results from the growth studies with ITCs and A. thaliana wild-type, an increased incubation time with these ITCs was required in order to observe an effect due to their lower vapor pressures. Exposure of 4.9 M BuITC for 2 min left a minor proportion of the filaments intact, which were lost after 5 min of treatment (Figure 3D). Adding BITC $(4.9 \mathrm{M})$ to the incubation chamber did not affect the filaments after $20 \mathrm{~min}$ of exposure. After $60 \mathrm{~min}$ however, the filaments were completely lost (Figure 3D). PEITC did not show any effect on microtubules even after $90 \mathrm{~min}$ of exposure (Figure 3D). These results demonstrate that ITCs cause microtubules in A. thaliana to disintegrate in a time- and dose-dependent manner, a potential possessed by both aliphatic and aromatic ITCs.

\section{AITC INDUCES TRANSCRIPTIONAL UPREGULATION OF HEAT SHOCK-GENES}

Based on of ITCs' reactive nature and previous studies with mammalian cells, ITCs are expected to target multiple intracellular components and trigger several responses in A. thaliana. In order to gain more insight into the ITC-induced implications in A. thaliana, a microarray analysis using a custom-printed array of AITC-treated and mock-treated plants was conducted. This preliminary screen revealed a potential upregulation of genes involved in various stress responses in particular heat shockresponse (data not shown). To verify this, the experiment was repeated and transcriptional regulation of a set of genes was analyzed in A. thaliana using quantitative PCR (qPCR). For this purpose, 11-days old plants were exposed to $0.5 \mathrm{M}$ AITC for $1 \mathrm{~h}$ (Table S1). Indeed, the expressions of HSP70, HSP90, and DNAJ were induced 7.0, 9.1, and 10.8 times compared to mocktreated control plants, respectively. These chaperone-encoding genes are commonly known for being involved in securing a proper folding of intracellular proteins and are induced by several abiotic stresses (Hartl, 1996). In addition, we found that expression of $S T Z$ was upregulated with a relative expression of 10.9 . $S T Z$ encodes a transcriptional regulator which expression has previously been associated with a response to drought-, salineand cold stress (Sakamoto et al., 2004). Hara and colleagues have previously reported a response on gene expression of glutathione S-transferase (GST) in A. thaliana treated with a low

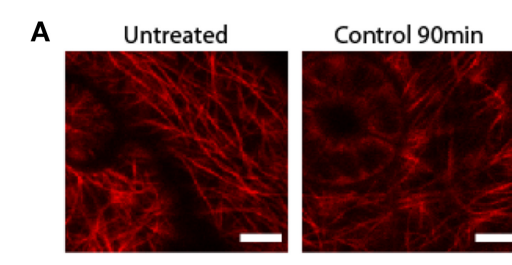

B

AITC added to incubation chamber [M], 2min treatments
0.5
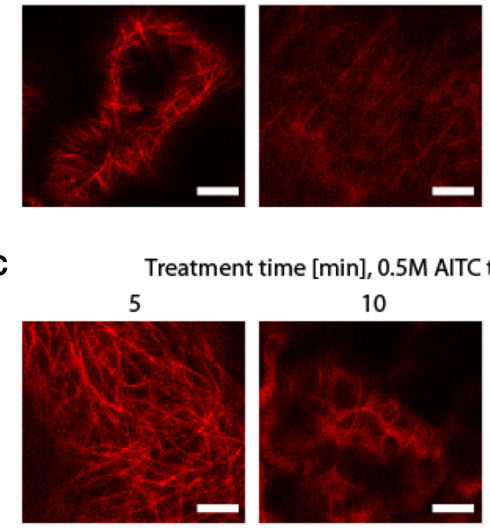

D

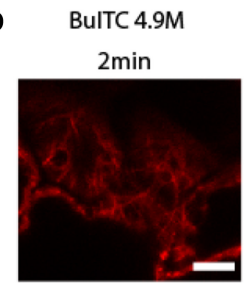

$5 \mathrm{~min}$

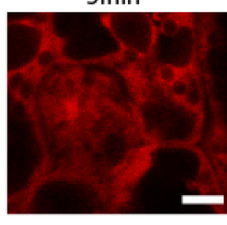

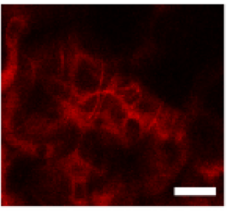

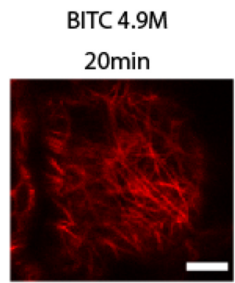

$60 \mathrm{~min}$

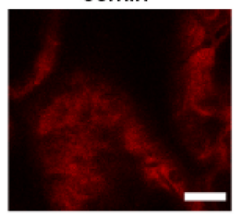

4.9
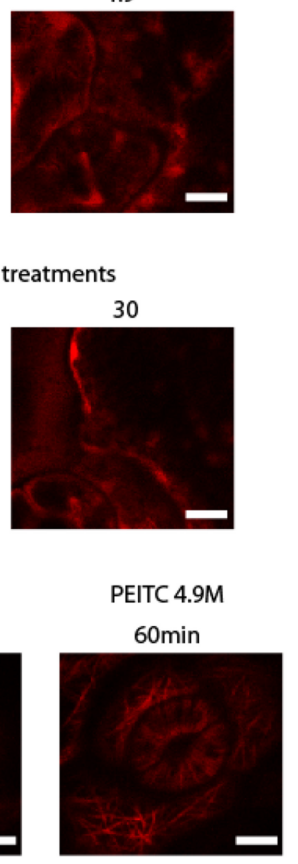

$90 \mathrm{~min}$

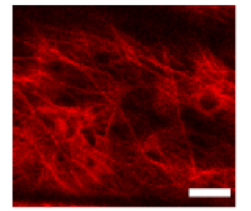

FIGURE 3 | Disintegration of microtubuli in $\boldsymbol{A}$. thaliana following ITC-treatment. (A) GFP fused N-terminally to $\alpha$-tubulin renders microtubular filaments in $A$. thaliana visible through confocal scanning microscope and proved to be unaffected by 90 min of incubation in chamber with only rapeseed oil added. (B) Microtubuli disintegration was dose-dependent as shown by comparing plants exposed to $0.5,1.0$, and 4.9 M AITC for $2 \mathrm{~min}$. (C) Microtubule filaments disintegration was also dependent on treatment time as shown by comparing plants exposed to $0.5 \mathrm{M}$ AITC for 2, 5, 10, and $30 \mathrm{~min}$. (D) BulTC and BITC also promoted loss of microtubule filament array in $A$. thaliana but required an increased treatment time compared to that of AITC-treatments. No effect on microtubules was observed by PEITC for up to 90 min of exposure. All plants used were 10 days old. Bar $=5 \mu \mathrm{m}$.

dose of PEITC (Hara et al., 2010). This included GSTU19 which was upregulated and GSTF6 and GSTF7 showing tendencies of an upregulated expression in response to ITC. However, none of these genes responded to $1 \mathrm{~h}$ exposure of $0.5 \mathrm{M}$ AITC in our studies. We also analyzed expression of two genes encoding UDPglucose-dependent glucosyltransferases (UGTs) due to their role in detoxification of xenobiotics. UGTs have also been reported to 
be upregulated in SFN-treated cancer cells (Basten et al., 2002; Messner et al., 2003). However, expressions of UGT84A1 and UGT75D1 were unaltered by the treatment. These findings serve as preliminary data to ITC-induced gene expression responses indicating that stress responses are likely to be triggered by ITCs in A. thaliana.

\section{ITCS INHIBIT PROLIFERATION AND PROMOTE CELL CYCLE ARREST IN RAT BLADDER CANCER CELLS}

Incubation of the rat bladder cancer cell line AY-27 with BITC, PEITC, AITC, and BuITC in the concentration range $1-100 \mu \mathrm{M}$ for $48 \mathrm{~h}$ resulted in a dose-dependent inhibition of cell proliferation (Figure 4A). The $\mathrm{IC}_{50}$ values obtained for BITC, PEITC, AITC, and BuITC were 3.6, 4.9, 13.2, and $26.1 \mu \mathrm{M}$, respectively. Growth cessation also proved to be a function of treatment durability as cells incubated with AITC for $24 \mathrm{~h}$ yielded $\mathrm{IC}_{50}$ value of $17.8 \mu \mathrm{M}$ whereas $72 \mathrm{~h}$ incubation resulted in an $\mathrm{IC}_{50}$ value of $4.9 \mu \mathrm{M}$ (Figure 4B). Furthermore, the influence of ITCs on cell cycle distribution of AY-27 cells was analyzed with flow cytometry (Figure 4C). Treatments with $5 \mu \mathrm{M}$ BITC and PEITC for $24 \mathrm{~h}$ resulted in 59 and $52 \%$ cells in $\mathrm{G}_{2} / \mathrm{M}$-phase, respectively, whereas cells incubated with vehicle control had only $29 \%$ of the cells in $\mathrm{G}_{2} / \mathrm{M}$-phase. Treatment with AITC or BuITC up to 15 or $40 \mu \mathrm{M}$, respectively, did not promote a shift in cell cycle distribution. However, incubation with $15 \mu \mathrm{M}$ AITC and $40 \mu \mathrm{M}$ BuITC forced 78 and $52 \%$ of the cells to reside in $\mathrm{G}_{2} / \mathrm{M}$-phase, respectively. Although the AITC-concentration required for a cell cycle arrest was higher compared to the other ITCs tested, the amount of cells arrested in $\mathrm{G}_{2}$ /M-phase induced by AITC is noteworthy suggesting that this compound may act stronger toward a cell cycle arrest than the other ITCs tested in this study. Remaining cells from AITC- and BITC-treatments were evenly distributed between $\mathrm{G}_{1}$ - and S-phase, whereas from BuITC- and PEITCtreatments cells in $\mathrm{G}_{1}$-phase dominated (Figure 4C). Moreover, concurrent with dosage was the effect of ITCs on cell morphology exemplified by AY-27 cells incubated with $10,15,30$, and $50 \mu \mathrm{M}$ AITC (Figure 4D). The decreased number of cells with increasing AITC-concentration was accompanied with increased proportion of the cells detached from the bottom surface of the growth flasks.

\section{ITCS PROMOTE DISINTEGRATION OF MICROTUBULES IN RAT BLADDER CANCER CELLS WHICH SUBSEQUENTLY ENTER APOPTOSIS}

To study the effect of ITCs on microtubuli in AY-27 we employed the same principal used with plants by transiently transfecting
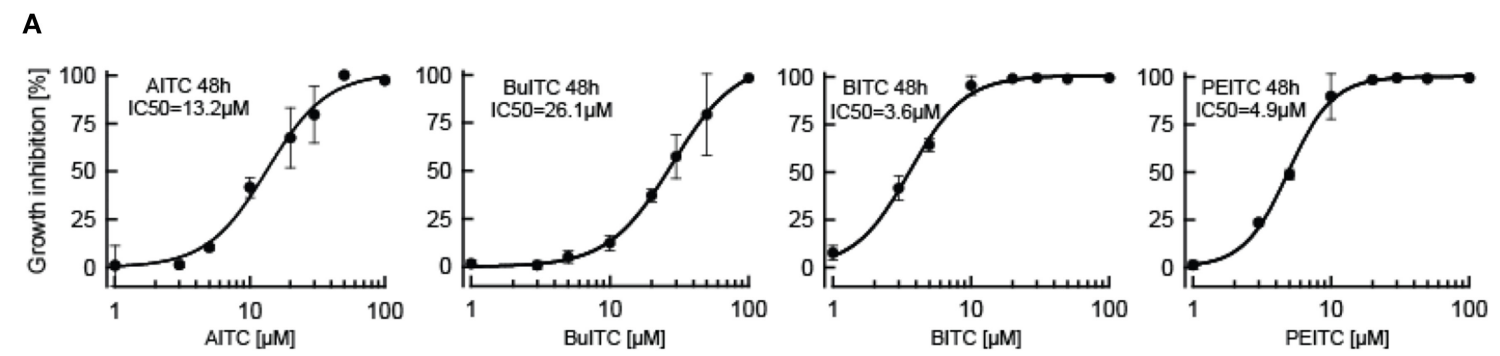

B
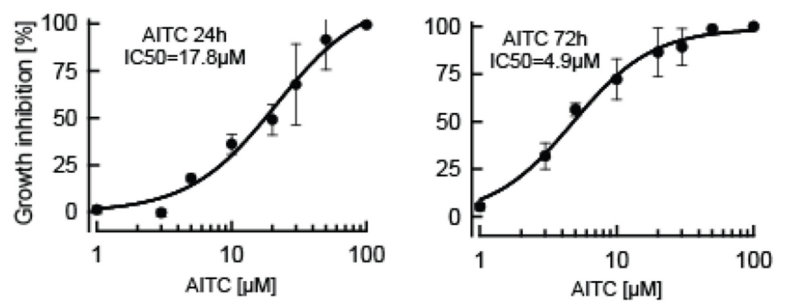

C
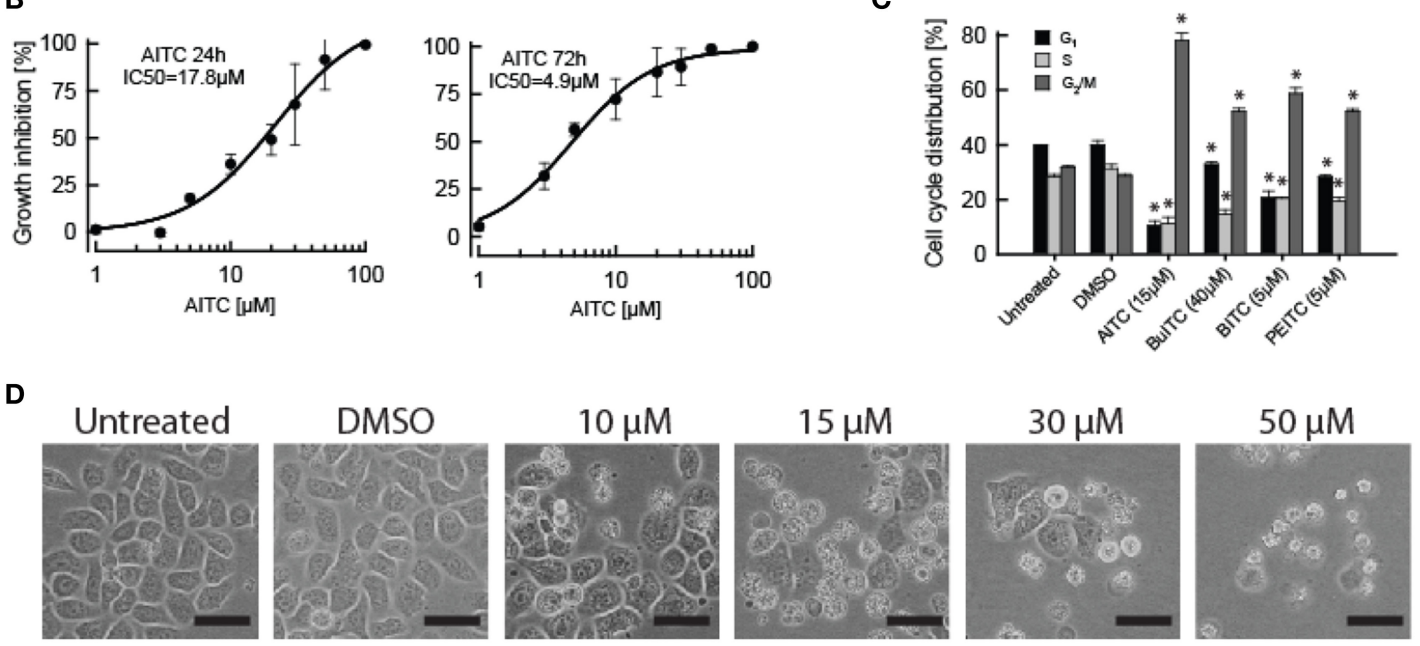

FIGURE 4 | Effects of ITCs on AY-27 proliferation, cell cycle distribution and morphology. (A) Dose-dependent response on growth of AY-27 cells treated with AITC, BuITC, BITC, and PEITC for $48 \mathrm{~h}$ demonstrated using MTT proliferation assay. (B) A time-dependent response in AY-27 proliferation to AITC-treatment was observed when 24 and $72 \mathrm{~h}$ treatments were included. Logistic regression curve fits were performed to calculate the sigmoidal graphs from which the $I_{50}$ values were extracted. Values represent means \pm s.d. of 5-6 replicates. (C)
Effect of ITCs on cell cycle distribution of AY-27 cells treated for $24 \mathrm{~h}$ analyzed using flow cytometry. Concentrations used were; AITC, $15 \mu \mathrm{M}$; BulTC, $40 \mu \mathrm{M}$; BITC, and PEITC, $5 \mu \mathrm{M}$. Solid bars indicate cells in $\mathrm{G}_{1}$-phase, light-gray bars indicate cells in $\mathrm{S}$-phase, dark-gray bars indicate cells in $\mathrm{G}_{2} / \mathrm{M}$-phase. Values represent means \pm s.d. of 3-6 replicates. The data were statistically analyzed by a two-tailed $t$-test. (D) Confluent AY-27 cells with increasing AITC-dosage following $24 \mathrm{~h}$ treatments. Bar $=$ $50 \mu \mathrm{m} .{ }^{*} p<0.05$ (unpaired one-tail t-test). 
cells to express a GFP- $\alpha$-tubulin fusion protein. Transfection with the plasmid PAGFP- $\alpha$-tubulin mediated the expression of GFP linked N-terminally to $\alpha$-tubulin in AY-27 cells. Using flow cytometry, the transfection efficiency was estimated to be $38 \%$. During treatments, the transient transfectants were transferred from an incubator with ideal temperature and gas composition for cell growth to room temperature with normal gas composition during microscopy. Microtubule filaments appeared unaffected in both untreated- and solvent-treated cells incubated under the microscope for up to $60 \mathrm{~min}$ (Figure 5A). In addition, the confluence and morphology of the control cells appeared unchanged during the incubation period. Furthermore, control cells transferred back to incubator or immediately harvested and seeded out in a $75 \mathrm{~cm}^{2}$ growth flask (in which cells usually were maintained) displayed normal growth and morphology (data not shown). Incubation with $50 \mu \mathrm{M}$ BuITC for 35 min significantly reduced the microtubule filaments in AY-27 (Figure 5B). After $55 \mathrm{~min}$ the filaments were completely absent and the cells displayed apoptotic blebs formed around the cells indicating a loss of microtubules followed by programmed cell death. This order of events appeared more distinct when AY-27 cells were treated with $25 \mu \mathrm{M}$ AITC which after $15 \mathrm{~min}$ of incubation led to a significant loss of microtubular filaments (Figure 5C). The filaments were completely disintegrated after 20-25 min with the subsequent emergence of apoptotic blebs surrounding the cells after $35 \mathrm{~min}$. These events merged when cells were treated with $50 \mu \mathrm{M}$ BITC, PEITC or AITC resulting in a rapid disintegration of microtubules combined with the formation of apoptotic blebs around the cells (Figure 5D). As the cells were transient transfectants where the plasmid copy number was not controlled we hypothesized whether the metabolic burden of maintaining plasmids would affect the response to ITC-treatment. However, both fluorescing and non-fluorescing cells displayed formation of apoptotic bodies around the cells after ITC-treatment (Figure 5E). As microtubuli have been highlighted to play an important role during formation of apoptotic bodies (Moss et al., 2006) we scouted a number of apoptotic cells for fluorescing filaments without success. These data show that externally supplied ITCs may enter bladder cancer cells and disrupt microtubular filaments hindering cells to complete the $\mathrm{G}_{2} / \mathrm{M}$-phase compelling cells to ultimately enter programmed cell death. The cell cycle arrest induced by ITCs as discussed above and shown in cancer cell from several sites has been further specified to be a mitotic arrest rather than a $\mathrm{G}_{2}$-arrest, being reasonable considering the vital role of microtubules during mitosis for segregation of chromosomes (Mi et al., 2008; Geng et al., 2011). Taken together, these data and previous reports support the fact that binding of ITCs to tubulin, causing disintegration of microtubular filaments, is an important mechanism by which ITCs lead to cell cycle arrest and apoptosis.

\section{DISCUSSION}

Previous studies have demonstrated that ITCs bind to tubulins, suppress the dynamic instability of microtubules and lead to
A.

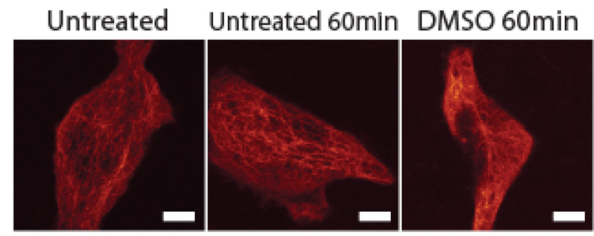

B

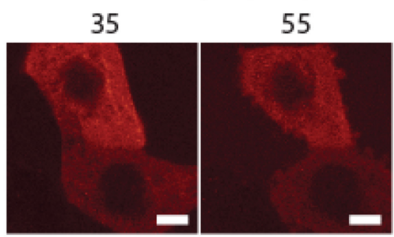

C AITC $25 \mu \mathrm{M}[\mathrm{min}]$

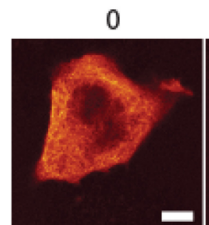
15 35 45

D

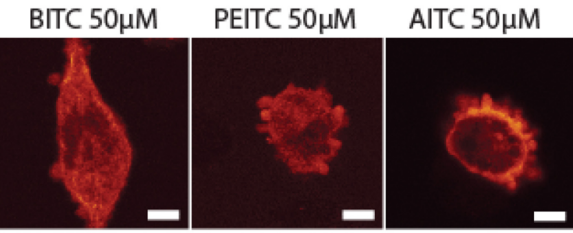

E

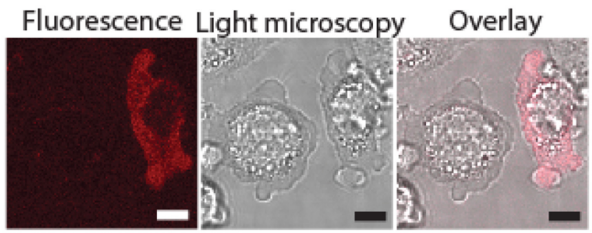

FIGURE 5 | Disintegration of microtubular filaments in AY-27 cells which subsequently enter apoptosis promoted by ITCs. (A) GFP-tagged microtubuli in transiently transfected AY-27 cells were unaffected by a $1 \mathrm{~h}$ incubation under the microscope with or without solvent $(0.1 \%$ DMSO) added. (B) AY-27 cells treated with $50 \mu \mathrm{M}$ BulTC for $35 \mathrm{~min}$ displayed a significant reduction in microtubules and formed apoptotic blebs after $55 \mathrm{~min}$ of treatment. (C) AITC $(25 \mu \mathrm{M})$ induced a significant loss of microtubules after 15 min of treatment with the subsequent formation of apoptotic bodies observed after $35 \mathrm{~min}$. (D) Treatment of AY-27 with $50 \mu \mathrm{M}$ BITC, PEITC or AITC for 5, 17, and $24 \mathrm{~min}$, respectively, reduced microtubule filaments and induced apoptosis as seen by the formation of apoptotic bodies. (E) Both transfected and non-transfected cells formed apoptotic blebs as a result from BITC-treatment $(50 \mu \mathrm{M})$. Bar $=5 \mu \mathrm{m}$. 
their disruption as a mechanism by which ITCs induce cell cycle arrest and inhibit cell proliferation of mammalian cancer cells (Azarenko et al., 2008; Mi et al., 2008; Geng et al., 2011). In plants, ITCs have been shown to inhibit growth but information about the underlying mechanisms is missing. In the present study we confirmed the ITC-induced disruption of microtubular filaments in rat bladder cancer cells and further revealed the same mechanism in the model plant A. thaliana. Exposure of $A$. thaliana to vapor of $0.1-3.4 \mathrm{M}$ AITC yielded a dose-dependent inhibition of growth (Figure 1B) and this was further showed to be time-related when seedlings were exposed to vapor of $0.5 \mathrm{M}$ AITC for 30,60 or $120 \mathrm{~min}$ (data not shown). The concurrent miscolored and bleached leaves observed following AITC-exposures (Figure 1B) indicate chlorophyll loss and are typical symptoms of oxidatively stressed plants. These traits were also observed when 5-weeks old plants of $A$. thaliana were applied with wateremulsions of MITC, AITC or PEITC in a previous report (Hara et al., 2010).

In a different study, in A. thaliana guard cells AITC was shown to increase the reactive oxygen species (ROS) content playing a role in stomatal closure (Khokon et al., 2011). ITC-induced ROS generation has also been demonstrated in human cancer cells subsequently to binding and conjugation of ITCs with the highly abundant redox mediator glutathione (GSH) (Zhang, 2000; Singh et al., 2005; Xiao et al., 2006; Mi et al., 2007, 2008). The conjugation reaction of GSH to ITC is carried out by the enzymes glutathione S-transferases (GSTs). Transcriptional upregulation of genes encoding GSTs has been reported to be induced by ITCs in mammalian cancer cells and has been suggested as a chemopreventive mechanism (Zhang et al., 1992; Talalay, 2000). GSTs are also present in A. thaliana and Hara et al. (2010) analyzed the transcript levels of a set of GSTs reporting an enhanced expression of GSTU19 in response to PEITC (Wagner et al., 2002). Expression of GSTU19 was not elevated by exposure to $0.5 \mathrm{M}$ for $1 \mathrm{~h}$ in the present study. However, when exposure time with $0.5 \mathrm{M}$ AITC was increased to $2 \mathrm{~h}$ we observed an increased expression level in all four replicates analyzed in a preliminary follow-up study. Taken together, seedlings of $A$. thaliana exposed to ITC display traits of oxidatively stressed plants which may derive from binding and/or conjugation of ITC with GSH, though further studies are required to clarify the interaction of ITC with GSH as well as the role of GSTs in ITC-exposed A. thaliana.

The reactivity of ITCs has been accredited the $-\mathrm{N}=\mathrm{C}=\mathrm{S}$ moiety with an $\mathrm{R}$ side chain dictating the specificity and potency. The presence of an aromatic component in the $\mathrm{R}$ group has proved to be important for the growth-inhibitory potential of an ITC supported by the present data in which PEITC and BITC exhibited a stronger inhibition of cell proliferation of AY-27 cells compared to AITC and BuITC (Figure 4A) (Jakubikova et al., 2005; Tang and Zhang, 2005; Mi et al., 2008). Our study showed activity of AITC, BuITC and BITC in A. thaliana (Figures 13) but could not range the ITCs according to order of potency as the compounds confer different vapor pressures. However, the direct application of ITC-solutions on A. thaliana showed that PEITC bleaches seedlings more efficiently than AITC and
MITC suggesting the predominating potency of aromatic ITCs in A. thaliana as in mammalian cells (Hara et al., 2010).

Although influenced by the R moiety, ITCs possess the ability to bind any accessible thiol group. Consequently, after entering a cell ITCs target numerous proteins containing cysteine in addition to GSH as discussed above. In human lung cancer cells, a number of protein targets antagonized by SFN and PEITC were identified (Mi et al., 2011). A similar study has not been conducted in ITC-exposed A. thaliana, but several of the proteins identified by Mi et al. (2011) constitute highly conserved proteins among eukaryotes leading to an assumption that proteins targeted by ITCs in A. thaliana may include, but are not limited to, some of the isoforms of the proteins identified as ITC-targets in mammalian cells. We showed an upregulation in gene expressions of HSP70, HSP90, and DNAJ encoding chaperones involved in protein quality control and may aid in refolding proteins that are covalently modified by ITCs possessing an altered threedimensional structure. However, many of the proteins targeted and modified by ITCs are likely to be degraded. This fate has been reported for $\alpha$ - and $\beta$-tubulins modified by ITCs in human lungand bladder cancer cells presumably degraded via ubiquitination (Mi et al., 2008, 2009; Geng et al., 2011). When the binding sites of ITCs on tubulins were investigated, it was shown that the majority of the free thiol groups on cysteine residues were accessible to ITCs although influenced by the R moiety and concentration (Mi et al., 2008). Geng et al. (2011) identified cysteine residues Cys347 and Cys376 in $\alpha$-tubulin and Cys12, Cys239, and Cys354 in $\beta$ tubulin from porcine cells as binding targets for AITC. Tubulins are proteins that are highly conserved among eukaryotes and amino acid sequence similarity between human and $A$. thaliana $\alpha$-tubulin has been reported to $83 \%$ (Ludwig et al., 1987). Of the 21 cysteine residues in $A$. thaliana ( 11 in $\alpha$ - and 10 in $\beta$-tubulin), 16 are highly conserved in mammalian cells including the identified targets for AITC mentioned above (Ludwig et al., 1987; Marks et al., 1987). This supports an order of events induced by ITCs in $A$. thaliana involving covalent modification of $\alpha$ - and $\beta$ tubulins at cysteine residues rendering the tubulins incapable of polymerizing with the subsequent disintegration of microtubule filaments. It remains an open question whether the ITC-bound tubulins are degraded in $A$. thaliana or undergo a refolding. Also, studies to elucidate the binding targets of ITCs in A. thaliana tubulins should be undertaken to improve our understanding of this mechanism.

In summary, the present study provides evidence of an ITCinduced growth inhibition of A. thaliana and disruption of microtubular filaments as a mechanism contributing to the observed phenotype. This mechanism was also shown in rat bladder cancer cells suggesting that plant- and mammalian cells may share several common traits in terms of highly conserved upstream binding targets and subsequent downstream events induced by ITCs. Our findings contribute to an improved understanding of the physiological role of the glucosinolate-myrosinase system by presenting new insight into the molecular mechanisms by which ITCs act in plants. Gained knowledge about the glucosinolatemyrosinase system may in turn expose clues to the underlying mechanisms of ITCs' anti-carcinogenic activity. 


\section{MATERIALS AND METHODS CHEMICALS AND KITS}

ITCs (>95\% purity), DMSO, Murashige-Skoog (MS), 3-(4,5dimethylthiazol-2-yl)-2,5-diphenyltetrazolium bromide (MTT), RPMI-1640 (including supplements), RNase, propidium iodide and Spectrum Plant Total RNA Kit were purchased from Sigma Aldrich (Norway). Rapeseed oil was bought at a local supermarket. Primers for qPCR were ordered from Eurofins MWG (Germany). QuantiTect Reverse Transcription Kit and RNaseFree DNase Set were purchased from QIAGEN (Norway). SYBRgreen and FugeneHD transfection reagent were purchased from Roche Applied Science (Norway). Four-chambered microscopy slides were purchased from Nunc (Norway).

\section{A. THALIANA LINES AND GROWTH}

A. thaliana wild-type was ecotype Col-0. The transformed A. thaliana Col-0 expressed GFP-tagged $\alpha$-tubulin under the control of a constitutive 35 S promoter (Ueda et al., 1999). Seeds of transgenic line were kindly provided by Dr. Ko Shimamoto, Nara Institute of Science and Technology, JP. Seeds of A. thaliana wild-type (Col-0 ecotype) and transgene line were sterilized with chlorine and ethanol before vernalized for 2 days in the absence of light. Plants were grown on MS-agar medium (MS, $2.15 \mathrm{~g} / \mathrm{l}$; sucrose, $20 \mathrm{~g} / \mathrm{l}$; agar, $6 \mathrm{~g} / \mathrm{l}$; $\mathrm{pH}$ 5.7) in a $16 \mathrm{~h}$ day/ $8 \mathrm{~h}$ night cycle at room temperature. Light intensity in growth chambers was measured to $70-80 \mu \mathrm{M} / \mathrm{m}^{\wedge} 2 / \mathrm{s}$.

\section{ITC-EXPOSURE OF A. THALIANA}

For ITC-treatment, 10-11 days old plants grown on a $9 \mathrm{~cm}$ petridish with MS-agar medium were used. The petri-dish containing the seedlings without lid was placed inside a $13 \mathrm{~cm}$ petri-dish containing a filter paper added $200 \mu \mathrm{l}$ of ITC-solution diluted in rapeseed oil in the given concentrations. The $13 \mathrm{~cm}$ petridish was sealed, allowing the seedlings to be exposed to the vapor from the ITC-solution. For studying the effect of AITC on growth and microtubules, $1 \mathrm{~h}$ and 2-30 min exposures, respectively, were employed. When applying BuITC, BITC or PEITC, exposure durations varied from 2 to $90 \mathrm{~min}$. Following exposure, seedlings were carefully picked up and transferred to a new petridish containing fresh MS-agar medium and grown as described above. Roots were covered with $0.1 \%(\mathrm{w} / \mathrm{v})$ agarose to prevent draft. Growth was monitored by capturing pictures from above on a daily basis. ITC-solutions were always prepared right before usage.

\section{qPCR OF AITC-TREATED A. THALIANA}

Using a scalpel, roots of AITC-treated A. thaliana wild-type plants were removed before snap-freezing the remaining plant material in liquid nitrogen. Total RNA was extracted using Spectrum Plant Total RNA Kit according to the manufacturer's protocol. During RNA extraction the samples were subjected to DNA digestion using RNase-Free DNase Set. RNA concentration in each sample was measured in duplicates using a NanoDrop 1000 (Thermo Scientific). cDNA was synthesized from $1 \mu \mathrm{g}$ RNA using QuantiTect Reverse Transcription Kit according to the manufacturer's instructions. A Lightcycler 480 (Roche Applied Science) was used to perform qPCR with SYBRgreen in 96-well plate format according to the manufacturer's procedure. The program used for qPCR consisted of a preincubation step $\left(95^{\circ} \mathrm{C}, 5 \mathrm{~min}\right)$, 45 amplification cycles $\left(95^{\circ} \mathrm{C}, 10 \mathrm{~s} ; 55^{\circ} \mathrm{C}, 10 \mathrm{~s} ; 72^{\circ} \mathrm{C}, 10 \mathrm{~s}\right)$, and a final melting curve analysis. Correct amplicons were verified by analysis of melting curves and amplicon lengths using gel electrophoresis. Cycle threshold values were calculated using the software Lightcycler 480 Software (Roche). PCR efficiency was calculated using the software LinRegPCR. Relative expression values were calculated using the software REST 2009 from QIAGEN. At4g24550.1 (Clathrin), At3g25800.1 (PP2A), and At4g34270.1 (TIP41-like) were used to normalize data. Primer sequences for housekeeping genes and the genes analyzed are given in Supplementary Table S2.

\section{AY-27 GROWTH AND PROLIFERATION ASSAY}

Rat bladder cancer cell line AY-27 (Arum et al., 2010) was kindly provided by Dr. S. Selman (Department of Urology, Medical College of Ohio, US). Monolayer culture of AY-27 cells was maintained in $75 \mathrm{~cm}^{2}$ flasks with RPMI-1640 supplemented with $10 \%$ $(\mathrm{v} / \mathrm{v})$ fetal bovine serum and $100 \mu \mathrm{g} / \mathrm{l}$ gentamicin at $37^{\circ} \mathrm{C}$ and $5 \% \mathrm{CO}_{2}$ in a humidified incubator. For proliferation assay, cells were grown in a 96-well plate starting with $5 \times 10^{3}$ cells per well. Cells were incubated for $24 \mathrm{~h}$ before treated with solvent (0.1\% DMSO) or freshly prepared solutions of ITCs. At ended treatments, cells were added $100 \mu \mathrm{l}$ MTT-solution $(0.5 \mathrm{mg} / \mathrm{ml})$ and incubated for $4 \mathrm{~h}$ from which $50 \mu \mathrm{l}$ was then removed. The remaining suspensions were mixed with $100 \mu \mathrm{l}$ acidified isopropanol for $20 \mathrm{~min}$ before absorbance at $595 \mathrm{~nm}$ was measured using a spectrophotometric plate reader.

\section{CELL CYCLE ANALYSIS}

For cell cycle analysis, $5 \times 10^{5}$ cells were incubated in $25 \mathrm{~cm}^{2}$ flasks for $24 \mathrm{~h}$ before treatment. Following treatment, harvested cells were resuspended and incubated with chilled methanol $\left(-20^{\circ} \mathrm{C}, 100 \%\right)$ for $15 \mathrm{~min}$. Pelleted cells were resuspended and incubated with $2 \mathrm{ml} \mathrm{RNase}(200 \mu \mathrm{g} / \mathrm{ml})$ for $45 \mathrm{~min}$ before pelleted and resuspended in $1.5 \mathrm{ml}$ propidium iodide $(50 \mu \mathrm{g} / \mathrm{ml})$. After 15 min incubation at room temperature, cell cycle distribution was analyzed using a Beckman Coulter Gallios flow cytometer with 20,000 cells per sample analyzed. The software Kaluza (Beckman Coulter) was used for data handling.

\section{TRANSFECTION OF AY-27}

Plasmid PAGFP- $\alpha$-tubulin (Tulu et al., 2003) was purified from overnight culture of transformed Escherichia coli DH5 $\alpha$ using Maxiprep kit following the manufacturer's protocol. DNA concentration was measured using a NanoDrop 1000 (Thermo Scientific). In a 96-well plate, $1.5 \times 10^{4}$ cells were incubated over night and medium was replaced with fresh medium. To each well, a solution of RPMI-1640 without serum added supplemented with $10 \mu \mathrm{g} / \mathrm{ml}$ of plasmid DNA and $4 \%$ (v/v) of FugeneHD transfection reagent was added the same volume as the volume of the medium in each well. After over night incubation, cells were washed with PBS, harvested and pooled. Transfection efficiency was determined using a Beckman Coulter Gallios flow cytometer with 5000 cells scanned for fluorescence. For confocal microscopy studies of ITC-treated transfected AY-27 cells, $8 \times 10^{4}$ cells per well were incubated in 4-well microscopy chambers over night. 


\section{SAMPLE PREPARATIONS AND CONFOCAL SCANNING MICROSCOPY}

From ITC-treated $A$. thaliana, a rosette leaf was excised and immediately analyzed using an inversed Leica TCS SP5 confocal microscope with a $63 \times$ NA 1.2 apochromat water immersion objective. GFP was excited with a $488 \mathrm{~nm}$ argon-laser and emission was detected in the range 500-590 $\mathrm{nm}$. Pinhole size was 1 airy unit. Pictures captured were of $1024 \times 1024$ formats with pixel size of $98.6 \mathrm{~nm}$. For cancer cells, a microscopy chamber with transfected AY-27 cells grown over night was inspected with the same microscope and settings as described above with the following changes: emission detection range was $495-560 \mathrm{~nm}$ and pictures captured were in the format $512 \times 512$ with pixel size $60.2 \mathrm{~nm}$. All data handling was performed using the software Leica Application Suite Advanced Fluorescence Lite. Apart from occasionally minor contrast-enhancements, all pictures were exported in an unedited raw format.

\section{ACKNOWLEDGMENTS}

We would like to thank Bjørnar Sporsheim for assistance on confocal microscope, Torfinn Sparstad for good advices concerning qPCR and technical assistance on harvesting plant material for qPCR, and Ragni Adelsten Stokland and Signe Elisabeth Åsberg for technical assistance on harvesting plant material for qPCR. We would also like to thank Kristin Grenstad Sæterbø for excellent technical assistance on flow cytometry, and Astrid Jullumstrø Feuerherm, Hanna Maja Tunset, Thuy Nguyen and Mari Sæther for their genuine concern and guidance regarding animal cell culture experiments. This study was supported by The Norwegian Research Council project 184146 "a systems biology approach for modeling of plant signaling and host defense" and a PhD grant from The Norwegian University of Science and Technology to Anders Øverby.

\section{SUPPLEMENTARY MATERIAL}

The Supplementary Material for this article can be found online at: http://www.frontiersin.org/journal/10.3389/fpls.2015.00006/ abstract

\section{REFERENCES}

AlKhatib, K., Libbey, C., and Boydston, R. (1997). Weed suppression with Brassica green manure crops in green pea. Weed Sci. 45, 439-445.

Ambrosone, C. B., McCann, S. E., Freudenheim, J. L., Marshall, J. R., Zhang, Y. S., and Shields, P. G. (2004). Breast cancer risk in premenopausal women is inversely associated with consumption of broccoli, a source of isothiocyanates, but is not modified by GST genotype. J. Nutr. 134, 1134-1138.

Arum, C. J., Anderssen, E., Tommeras, K., Lundgren, S., Chen, D., and Zhao, C. M. (2010). Gene expression profiling and pathway analysis of superficial bladder cancer in rats. Urology 75, 742-749. doi: 10.1016/j.urology.2009.03.008

Azarenko, O., Okouneva, T., Singletary, K. W., Jordan, M. A., and Wilson, L. (2008). Suppression of microtubule dynamic instability and turnover in MCF7 breast cancer cells by sulforaphane. Carcinogenesis 29, 2360-2368. doi: 10.1093/carcin/bgn241

Basten, G. P., Bao, Y. P., and Williamson, G. (2002). Sulforaphane and its glutathione conjugate but not sulforaphane nitrile induce UDP-glucuronosyl transferase (UGT1A1) and glutathione transferase (GSTA1) in cultured cells. Carcinogenesis 23, 1399-1404. doi: 10.1093/carcin/23.8.1399

Bialy, Z., Oleszek, W., Lewis, J., and Fenwick, G. R. (1990). Allelopathic potential of glucosinolates (mustard oil glycosides) and their degradation products against wheat. Plant Soil 129, 277-281.

Boydston, R. A., and Hang, A. (1995). Rapeseed (Brassica napus) green manure crop suppresses weeds in potato (Solanum tuberosum). Weed Technol. 9, 669-675.
Brennan, P., Hsu, C. C., Moullan, N., Szeszenia-Dabrowska, N., Lissowska, J., Zaridze, D., et al. (2005). Effect of cruciferous vegetables on lung cancer in patients stratified by genetic status: a mendelian randomisation approach. Lancet 366, 1558-1560. doi: 10.1016/S0140-6736(05)67628-3

Cheung, K. L., and Kong, A. N. (2010). Molecular targets of dietary phenethyl isothiocyanate and sulforaphane for cancer chemoprevention. AAPS J. 12, 87-97. doi: 10.1208/s12248-009-9162-8

Cornblatt, B. S., Ye, L. X., Dinkova-Kostova, A. T., Erb, M., Fahey, J. W. Singh, N. K., et al. (2007). Preclinical and clinical evaluation of sulforaphane for chemoprevention in the breast. Carcinogenesis 28, 1485-1490. doi: 10.1093/carcin/bgm049

Geng, F., Tang, L., Li, Y., Yang, L., Choi, K.-S., Kazim, A. L., et al. (2011). Allyl isothiocyanate arrests cancer cells in mitosis, and mitotic arrest in turn leads to apoptosis via Bcl-2 protein phosphorylation. J. Biol. Chem. 286, 32259-32267. doi: 10.1074/jbc.M111.278127

Halkier, B. A., and Gershenzon, J. (2006). Biology and biochemistry of glucosinolates. Annu. Rev. Plant Biol. 57, 303-333. doi: 10.1146/annurev.arplant.57.032905.105228

Hara, M., Harazaki, A., and Tabata, K. (2013). Administration of isothiocyanates enhances heat tolerance in Arabidopsis thaliana. Plant Growth Regul. 69, 71-77. doi: 10.1007/s10725-012-9748-5

Hara, M., Yatsuzuka, Y., Tabata, K., and Kuboi, T. (2010). Exogenously applied isothiocyanates enhance glutathione S-transferase expression in Arabidopsis but act as herbicides at higher concentrations. J. Plant Physiol. 167, 643-649. doi: 10.1016/j.jplph.2009.11.006

Haramoto, E. R., and Gallandt, E. R. (2005). Brassica cover cropping: I. Effects on weed and crop establishment. Weed Sci. 53, 695-701. doi: 10.1614/WS-04162R.1

Hartl, F. U. (1996). Molecular chaperones in cellular protein folding. Nature 381, 571-580. doi: 10.1038/381571a0

Jakubikova, J., Bao, Y. P., and Sedlak, J. (2005). Isothiocyanates induce cell cycle arrest, apoptosis and mitochondrial potential depolarization in HL-60 and multidrug-resistant cell lines. Anticancer Res. 25, 3375-3386.

Joseph, M. A., Moysich, K. B., Freudenheim, J. L., Shields, P. G., Bowman, E. D., Zhang, Y. S., et al. (2004). Cruciferous vegetables, genetic polymorphisms in glutathione S-transferases $\mathrm{M} 1$ and $\mathrm{T} 1$, and prostate cancer risk. Nutr. Cancer 50, 206-213. doi: 10.1207/s15327914nc5002_11

Khokon, M. A. R., Jahan, M. S., Rahman, T., Hossain, M. A., Muroyama, D., Minami, I., et al. (2011). Allyl isothiocyanate (AITC) induces stomatal closure in Arabidopsis. Plant Cell Environ. 34, 1900-1906. doi: 10.1111/j.13653040.2011.02385.x

Kissen, R., and Bones, A. M. (2009). Nitrile-specifier proteins involved in glucosinolate hydrolysis in Arabidopsis thaliana. J. Biol. Chem. 284, 12057-12070. doi: 10.1074/jbc.M807500200

London, S. J., Yuan, J. M., Chung, F. L., Gao, Y. T., Coetzee, G. A., Ross, R. K., et al. (2000). Isothiocyanates, glutathione S-transferase M1 and T1 polymorphisms, and lung-cancer risk: a prospective study of men in Shanghai, China. Lancet 356, 724-729. doi: 10.1016/S0140-6736(00)02631-3

Ludwig, S. R., Oppenheimer, D. G., Silflow, C. D., and Snustad, D. P. (1987) Characterization of the alpha-tubulin gene family of Arabidopsis-thaliana. Proc. Natl. Acad. Sci. U.S.A. 84, 5833-5837. doi: 10.1073/pnas.84.16.5833

Marks, M. D., West, J., and Weeks, D. P. (1987). The relatively large beta-tubulin gene family of arabidopsis contains a member with an unusual transcribed 5 ' noncoding sequence. Plant Mol. Biol. 10, 91-104. doi: 10.1007/BF000 16147

Messner, B., Thulke, O., and Schaffner, A. R. (2003). Arabidopsis glucosyltransferases with activities toward both endogenous and xenobiotic substrates. Planta 217, 138-146. doi: 10.1007/s00425-002-0969-0

Mi, L., Hood, B. L., Stewart, N. A., Xiao, Z., Govind, S., Wang, X., et al. (2011). Identification of potential protein targets of isothiocyanates by proteomics. Chem. Res. Toxicol. 24, 1735-1743. doi: 10.1021/tx2002806

Mi, L. X., Gan, N. Q., Cheema, A., Dakshanamurthy, S., Wang, X. T., Yang, D. C. H., et al. (2009). Cancer preventive isothiocyanates induce selective degradation of cellular alpha- and beta-tubulins by proteasomes. J. Biol. Chem. 284, 17039-17051. doi: 10.1074/jbc.M901789200

Mi, L. X., Wang, X. T., Govind, S., Hood, B. L., Veenstra, T. D., Conrads, T. P., et al. (2007). The role of protein binding in induction of apoptosis by phenethyl isothiocyanate and sulforaphane in human non-small lung cancer cells. Cancer Res. 67, 6409-6416. doi: 10.1158/0008-5472.CAN-07-0340 
Mi, L. X., Xiao, Z., Hood, B. L., Dakshanamurthy, S., Wang, X. T., Govind, S., et al. (2008). Covalent binding to tubulin by isothiocyanates - A mechanism of cell growth arrest and apoptosis. J. Biol. Chem. 283, 22136-22146. doi: 10.1074/jbc.M802330200

Moss, D. K., Betin, V. M., Malesinski, S. D., and Lane, J. D. (2006). A novel role for microtubules in apoptotic chromatin dynamics and cellular fragmentation. J. Cell Sci. 119, 2362-2374. doi: 10.1242/jcs.02959

Nakamura, Y. (2009). "Chemoprevention by isothiocyanates: molecular basis of apoptosis induction," in Food Factors for Health Promotion, Vol. 61, ed T. Yoshikawa (Basel: Karger), 170-181. doi: 10.1159/000212749

Navarro, S. L., Li, F., and Lampe, J. W. (2011). Mechanisms of action of isothiocyanates in cancer chemoprevention: an update. Food Funct. 2, 579-587. doi: 10.1039/c1fol0114e

Norsworthy, J. K., Malik, M. S., Jha, P., and Oliveira, M. J. (2006). Effects of isothiocyanates on purple (Cyperus rotundus L.) and yellow nutsedge (Cyperus esculentus L.). Weed Biol. Manag. 6, 131-138. doi: 10.1111/j.14456664.2006.00208.x

Norsworthy, J. K., and Meehan, J. T. (2005). Use of isothiocyanates for suppression of Palmer amaranth (Amaranthus palmeri), pitted morningglory (Ipomoea lacunosa), and yellow nutsedge (Cyperus esculentus). Weed Sci. 53, 884-890. doi: 10.1614/WS-05-056R.1

Ohta, Y., Takatani, K., and Kawakishi, S. (1995). Decomposition rate of allyl isothiocyanate in aqueous-solution. Biosci. Biotechnol. Biochem. 59, 102-103. doi: 10.1271/bbb.59.102

Sakamoto, H., Maruyama, K., Sakuma, Y., Meshi, T., Iwabuchi, M., Shinozaki, K., et al. (2004). Arabidopsis Cys2/His2-type zinc-finger proteins function as transcription repressors under drought, cold, and high-salinity stress conditions. Plant Physiol. 136, 2734-2746. doi: 10.1104/pp.104. 046599

Seow, A., Yuan, J. M., Sun, C. L., Van den Berg, D., Lee, H. P., and Yu, M. C. (2002). Dietary isothiocyanates, glutathione S-transferase polymorphisms and colorectal cancer risk in the Singapore Chinese Health Study. Carcinogenesis 23, 2055-2061. doi: 10.1093/carcin/23.12.2055

Shapiro, T. A., Fahey, J. W., Dinkova-Kostova, A. T., Holtzclaw, W. D., Stephenson, K. K., Wade, K. L., et al. (2006). Safety, tolerance, and metabolism of broccoli sprout glucosinolates and isothiocyanates: a clinical phase I study. Nutr. Cancer 55, 53-62. doi: 10.1207/s15327914nc5501_7

Singh, S. V., Srivastava, S. K., Choi, S., Lew, K. L., Antosiewicz, J., Xiao, D., et al. (2005). Sulforaphane-induced cell death in human prostate cancer cells is initiated by reactive oxygen species. J. Biol. Chem. 280, 19911-19924. doi: 10.1074/jbc.M412443200

Talalay, P. (2000). Chemoprotection against cancer by induction of Phase 2 enzymes. Biofactors 12, 5-11. doi: 10.1002/biof.5520120102

Tang, L., and Zhang, Y. S. (2005). Mitochondria are the primary target in isothiocyanate-induced apoptosis in human bladder cancer cells. Mol. Cancer Ther. 4, 1250-1259. doi: 10.1158/1535-7163.MCT05-0041

Tang, L., Zirpoli, G. R., Guru, K., Moysich, K. B., Zhang, Y. S., Ambrosone, C. B., et al. (2008). Consumption of raw cruciferous vegetables us inversely associated with bladder cancer risk. Cancer Epidemiol. Biomarkers Prev. 17, 938-944. doi: 10.1158/1055-9965.EPI-07-2502
Tulu, U. S., Rusan, N. M., and Wadsworth, P. (2003). Peripheral, non-centrosomeassociated microtubules contribute to spindle formation in centrosomecontaining cells. Curr. Biol. 13, 1894-1899. doi: 10.1016/j.cub.2003.10.002

Ueda, K., Matsuyama, T., and Hashimoto, T. (1999). Visualization of microtubules in living cells of transgenic Arabidopsis thaliana. Protoplasma 206, 201-206. doi: 10.1007/BF01279267

Vaughn, S. F., and Boydston, R. A. (1997). Volatile allelochemicals released by crucifer green manures. J. Chem. Ecol. 23, 2107-2116. doi: 10.1023/B:JOEC.0000006432.28041.82

Wagner, U., Edwards, R., Dixon, D. P., and Mauch, F. (2002). Probing the diversity of the arabidopsis glutathione S-transferase gene family. Plant Mol. Biol. 49, 515-532. doi: 10.1023/A:1015557300450

Wolf, R. B., Spencer, G. F., and Kwolek, W. F. (1984). Inhibition of velvetleaf (abutilon-theophrasti) germination and growth by benzyl isothiocyanate, a natural toxicant. Weed Sci. 32, 612-615.

Xiao, D., Lew, K. L., Zeng, Y., Xiao, H., Marynowski, S. W., Dhir, R., et al. (2006). Phenethyl isothiocyanate-induced apoptosis in PC-3 human prostate cancer cells is mediated by reactive oxygen species-dependent disruption of the mitochondrial membrane potential. Carcinogenesis 27, 2223-2234. doi: 10.1093/carcin/bgl087

Yamane, A., Fujikura, J., Ogawa, H., and Mizutani, J. (1992). Isothiocyanates as alleopathic compounds from rorippa-indica hiern (cruciferae) roots. J. Chem. Ecol. 18, 1941-1954. doi: 10.1007/BF00981918

Zhang, Y. S. (2000). Role of glutathione in the accumulation of anticarcinogenic isothiocyanates and their glutathione conjugates by murine hepatoma cells. Carcinogenesis 21, 1175-1182. doi: 10.1093/carcin/21.6.1175

Zhang, Y. S. (2004). Cancer-preventive isothiocyanates: measurement of human exposure and mechanism of action. Mutat. Res. 555, 173-190. doi: 10.1016/j.mrfmmm.2004.04.017

Zhang, Y. S., Talalay, P., Cho, C. G., and Posner, G. H. (1992). A major inducer of anticarcinogenic protective enzymes from broccoli - isolation and elucidation of structure. Proc. Natl. Acad. Sci. U.S.A. 89, 2399-2403. doi: $10.1073 /$ pnas.89.6.2399

Conflict of Interest Statement: The authors declare that the research was conducted in the absence of any commercial or financial relationships that could be construed as a potential conflict of interest.

Received: 19 September 2014; accepted: 05 January 2015; published online: 22 January 2015.

Citation: Øverby A, Bevre MS, Thangstad OP and Bones AM (2015) Disintegration of microtubules in Arabidopsis thaliana and bladder cancer cells by isothiocyanates. Front. Plant Sci. 6:6. doi: 10.3389/fpls.2015.00006

This article was submitted to Plant Physiology, a section of the journal Frontiers in Plant Science.

Copyright (C) 2015 Øverby, Bavre, Thangstad and Bones. This is an open-access article distributed under the terms of the Creative Commons Attribution License (CC BY). The use, distribution or reproduction in other forums is permitted, provided the original author(s) or licensor are credited and that the original publication in this journal is cited, in accordance with accepted academic practice. No use, distribution or reproduction is permitted which does not comply with these terms. 